Proceedings

\title{
Photographic Rhapsodies. Pictures for Designing Architecture, Architecture for Designing Pictures ${ }^{\dagger}$
}

\author{
Marta Magagnini and Nicolò Sardo * \\ "Eduardo Vittoria" School of Architecture and Design, University of Camerino, 62032 Camerino, Italy; \\ marta.magagnini@unicam.it \\ * Correspondence: nicolo.sardo@unicam.it \\ + Presented at the International and Interdisciplinary Conference IMMAGINI? Image and Imagination \\ between Representation, Communication, Education and Psychology, Brixen, Italy, 27-28 November 2017.
}

Published: 1 December 2017

\begin{abstract}
This essay reflects on the intersection between architecture and photography, or better, between the architecture project and the photography project. The representation of architecture and the urban landscape is investigated through selected methods and trends that in recent years have characterized both the work of some photographers/artists and the design attitudes of those architects that for the birth of the architectural project use the photographic image for mediation. The cornerstone of the critical analysis is the manipulation of the image, techniques for doing so, and the applications and facets of sense and meaning that the desire for perceptual estrangement produces for the two goals: doing art or doing architecture.
\end{abstract}

Keywords: architectural photography; editing; manipulation; mimesis; birth of the project

\section{Introduction}

Already in the 1900s, architectural photography was characterized as a hybrid area between the two professions of the architect and the photographer-not by chance are many photographs of architecture made precisely by architects - and the photograph itself became a tool, if not for the project, for its representation. Today, however, this is not only about a shared interdisciplinary path nor reciprocal instrumentality. In recent years, there has been an unstoppable attitude towards manipulating photographic images that involves both worlds in parallel. In this sense, the photography (of architecture) has developed some trends that lead to transfiguration of the subject represented, to the point that it has become completely reconstituted. In the architectural project, instead, photographs have played an increasingly active part such that they definitively condition the project. On the one hand, thanks to computer graphics, photographic realism has unquestionably monopolized the final phase of representing the project in recent decades; on the other hand, cut and paste, from art to architecture, has opened and continues to open new roads for the architectural project in itself.

In photography, the sense of the operation itself ends up with its meaning reversed: it is space that is recreated ad hoc for representation, with procedures ranging from mimesis to the real construction of new realities and elements that increasingly move away from a concrete reference to reach completely digital forms. In architecture instead, the photograph becomes a tool for composition as well as representation: its images offer both "figures" and "backgrounds", whose editing touches the formal genesis of the spaces. 


\section{Pictures for Designing Architecture: Editing Strategies for Contemporary Architectural Composition}

The invention of photography became official in 1839 and only twenty years passed between the first daguerreotypes and photomontages created with the camera obscura [1]. Shortly after photographs began to enter middle-class homes in Victorian England, the first scrapbooks were created, albums full of photographic collages [2]. These short historical times reveal the objective nature of the photograph, which immediately loaned itself to manipulation, for reasons both technical and-especially-ontological. In fact, as John Berger notes, photographs "do not in themselves carry any certain meaning, because they are like images in the memory of a stranger" and they lend themselves to any use precisely for this reason [3] (p. 59). The photographed object, which that "stranger" deemed worthy of memory, is something that anyone can appropriate to observe the original "recognition" that saved it from lost history.

This intrinsic nature is also the reason why, at the beginning of the twentieth century, the photograph began to be used to represent the architectural project. The year 1910 marks the official date when the photograph entered architectural design [4]. The commissioner of the competition for the National Bismarck Memorial requested participants to create perspectives pasted onto some photos of the Elisenhöhe Hill. Thus began a new practice in which international architecture competitions began to systematically request "photo perspectives" [5] of the project inserted within its context, that is, glued onto a photograph of something to be conserved even after the new construction was complete.

The photograph has been used in many ways throughout the history of the project in the twentieth and twenty-first centuries, along with many types of editing [6]. But this intervention, which mainly affects contemporary imagery, is concentrated not so much on representation, on rendering a well-defined project, as on the conception phase of the project itself, where the photograph becomes a heuristic and creative tool in support of design.

Beginning with sketches by Le Corbusier or Oscar Niemeyer and continuing up to the sketchbooks of Steven Holl, small interventions of [photographic] collage allow a designed thought to be directly verified. With this strategy, the architect quickly establishes whether the idea is satisfactory or not. For some contemporary architects, instead, editing is a slow job of stratifying thoughts, subject to modulation and variation and experimenting with language.

One of the needs of contemporary architecture has been confirmed: the need to confront pre-existence, because any new architectural project-object will itself be immersed in a landscape-collage [7], a superposition of physical traces with which to interact. The landscape is a real place, but also a place of memories. It is a formal landscape to draw on to reinvent the form itself. An investigation of designs by the so-called contemporary Italian "architect-collage artists" (Carmelo Baglivo, Cherubino Gambardella, Luca Galofaro, Beniamino Servino, and others that are more or less occasional) highlights how these architects do not use the cut-and-paste technique (which is now almost exclusively digital, except the rare exceptions of exceptional designers such as Cherubino Gambardella) to create images as goals in themselves or final representations of something designed elsewhere and otherwise, but as a compositional strategy. The fragment is intended as a form in itself, to be recomposed, reassembled to combine past and future in an ideal way. In addition, rather than adding and stratifying, one can at times subtract or cancel out portions of [architectural] figures to recover the background and define new [architectural] forms. In this case, the language of the final image derives from that of the initial photograph. The same is true of the content: the manipulation is fed and appropriates a language without the pretext of creating a new one. The idea is to completely change the meaning of a recognizable starting element [8]. 


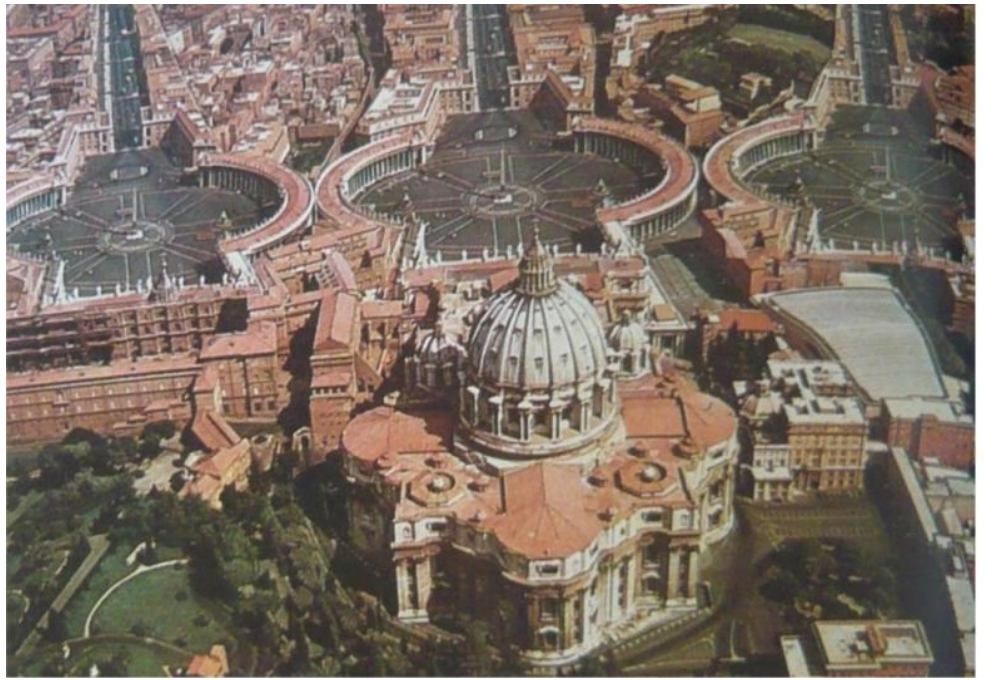

(a)

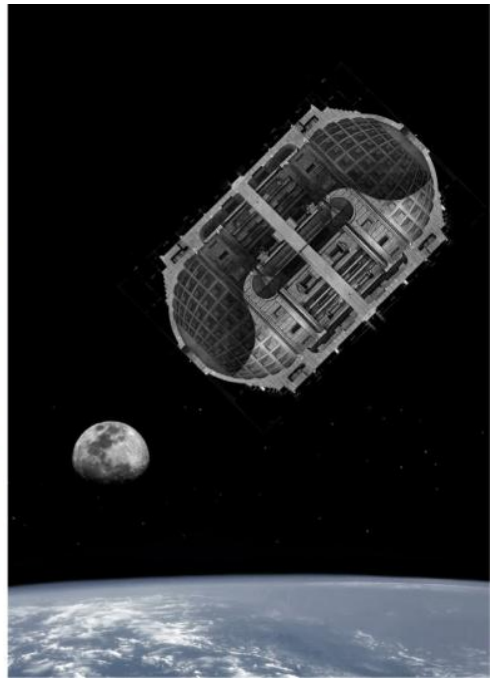

(b)

Figure 1. (a) Hans Dieter Schaal, Roma Arch-collages, 1977; (b) Luca Galofaro, Stazione spaziale Ritorni, 2010.

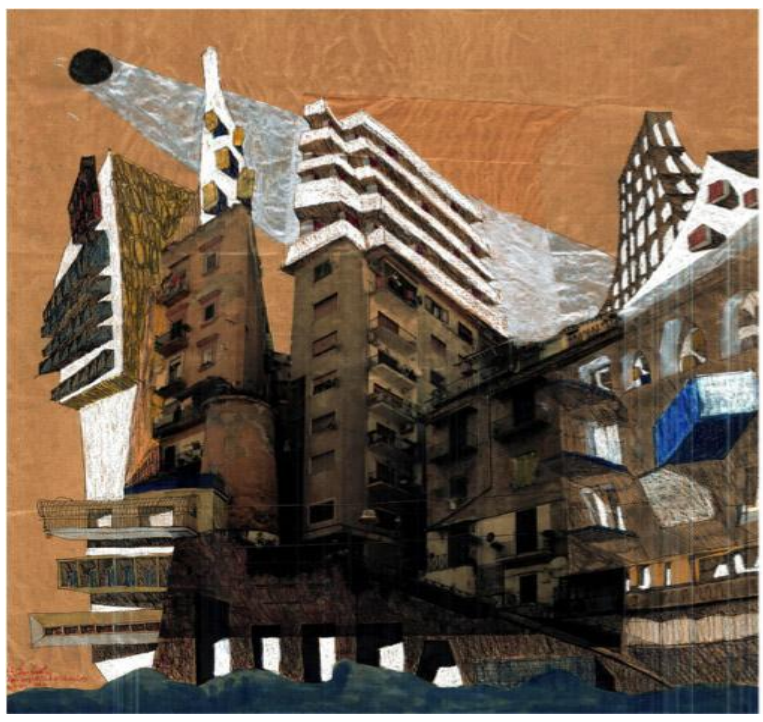

(a)

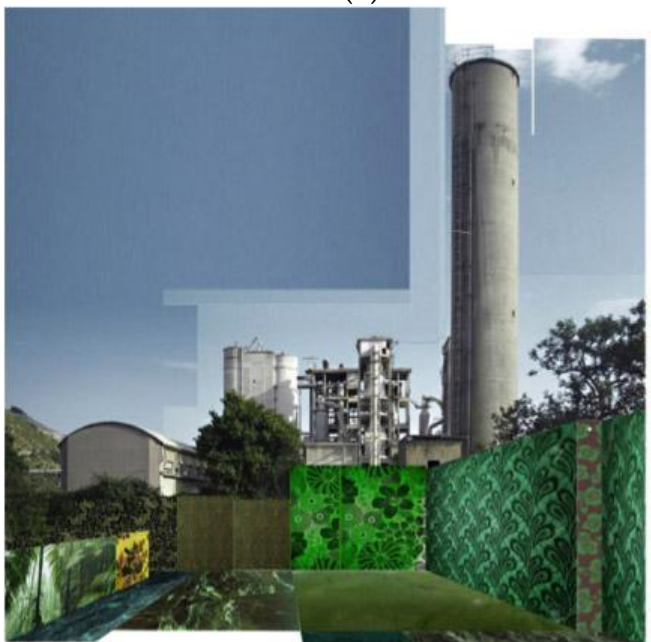

(c)

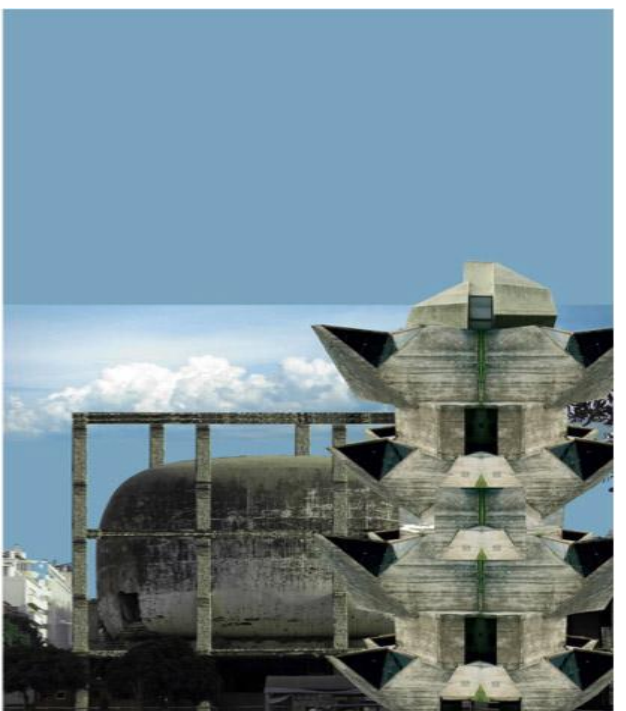

(b)

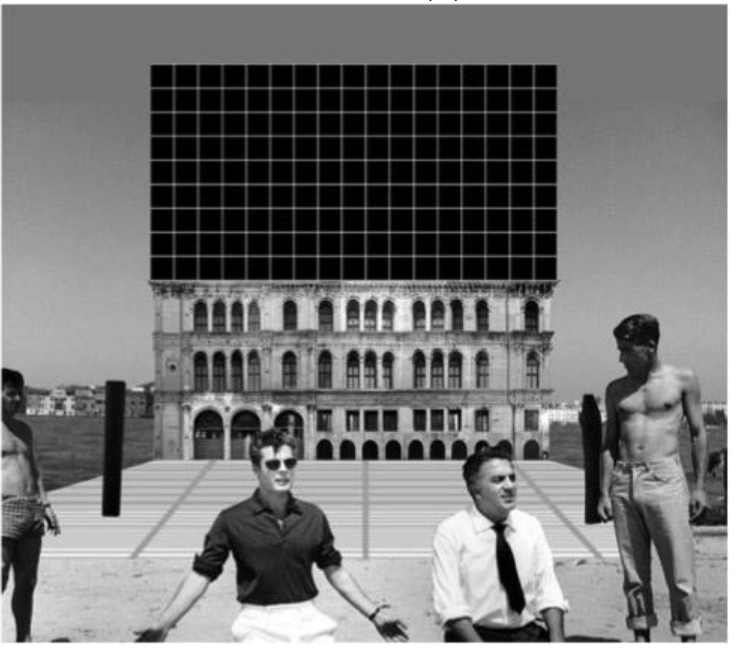

(d)

Figure 2. (a) Cherubino Gambardella, La vita con gli oggetti, 2011; (b) Luca Galofaro, Postcard from Beirut, 2013; (c) Beniamino Servino, Il giardino protetto, 2015; (d) Carmelo Baglivo, Palazzo veneziano, 2013. 
In reality, this is not an entirely new approach. In the 1970s, in fact, collage had its age d'or. Among the many international figures of "architect-collage artists", it is interesting to recall Hans Dieter Schaal, who, after a long stay in Rome, realized in 1977 a series of "re-seen and corrected" postcards. The observer is presented with systematic changes in the imagery of the Eternal City, through the duplication of its most unique, recognized buildings that pertain to collective memory. This formed the series Rome Arch-collages (Figure 1a). In one of these images, for example, the German architect triples St. Peter's Square and its colonnade, and adds another two, one to the left and one to the right: with this operation, a single urban device generates formally identical spaces that are structurally different because they dialogue with different contexts and generate different fabrics. What is evinced in Schaal's work is a reflection on the form and its meaning, which changes according to the position, on how to intervene and grow an urban fabric, and on the sense of a formal, equal reproduction.

But for Schaal, this operation remains a unicum in his production of designs and in particular did not produce concrete projects. Editing for some designers today is instead a favoured tool with respect to other techniques of design and communication, so much so that the images from this or that designer become recognizable; the practice has become "authorial" thanks to the inexhaustible potential of the technique. There are those that use descriptive geometry and design on photographic perspectives (Figure 2a,c,d) and those that instead choose cuttings to work with flat geometries, concentrating exclusively on the layers (Figures $1 \mathrm{~b}$ and $2 \mathrm{~b}$ ). The modernity of this analogue tool, which also loans itself to the digital realm, has undoubtedly important value in delineating a history of the contemporary project. This is true given the wide use it has found in the work not only of architects, but also of many contemporary artists: those who use photographs as the basis for the design (Rachel Whiteread) or those who adopt editing as an autonomous language, which can become a design solution (Gianfranco Botto and Roberta Bruno).

Using cut and paste, each designer not only experiments with their own stylistic search, but drafts true architectural theories for images, simultaneously throwing down the basis for future projects. Editing is a method that makes a selection of fragments to reaffirm memory as acquired models. A language is not invented ex novo, but is derived from already known registers, acting with miniscule technical interventions (addition, subtraction, multiplication...), which then become characteristic of a certain practice of architectural composition. The design of architecture, therefore, can only be realized with cut and paste, by nature of the design approach: one cannot begin with raw starting material because the desire is not to create autonomous, original forms, but to record the work within a network of signs and meanings.

\section{Architecture for Designing Pictures: The Representation of "Other" Realities}

Time and light intersect when a photographic image is made, but both of these elements create problems when reality is manipulated. Manipulation can proceed a posteriori-operating in the cracks allows depictions to be processed - but can also develop well before by recreating a specific interstice a priori.

If the particular relationship between photograph and reality has always been up for debate, what seems clear in the productions highlighted here is how the reality of the photograph itself can become, more than ever, ephemeral and virtual.

Any instrumental value of the image seems to disappear then: the image, the unique protagonist, aspires to be built as a subject, and reality is not only a servant. In this way the concept of a photograph as a testimony "that the thing was there" [9] (p. 78) loses strength, to instead reclaim its superiority over the "thing" itself.

If on the one hand some developments tend towards "mimesis", to the construction of a feasible reality, other productions deliberately establish an "impossible", imagined reality. "Imagery implies liberation with respect to the literal determination, the invention of new content, displaced, which introduce a symbolic dimension" [10] (p. 19). 
The relationship with the subject is thus developed in the folds of dialectics between "convention" and interpretation. "No genetic narration of the origin of the photo, no matter how detailed and careful, can logically guarantee the fidelity of that photo" [11] (p. 124).

If the photograph, having overcome its documentary function, has now clarified its capacity to deliver a "reading of the world", this world seems to be not only already interpreted, explained, mirrored, but is folded, redefined, and reconstructed.

But what do the images of "false" photographs on architecture and its representation tell us? In the fiction of the staging, a "truth" about the deeper mechanisms of representation and its subject can possibly be found. Basically, the credibility of the image does not create problems for the deeper sense of operating, but allows the meaning of the construction of the depiction to be analyzed with greater freedom.

In order to analyze the various procedures initiated by photographs that will be examined, three guiding themes have been identified.

\section{1. "Transfigured" Reality}

Processing proceeds subtly, always maintaining a high degree of relationship to reality. This is rather shown through a "filter" that modifies its character. The actions made are often all internal to the mechanisms of the photographic tool: blurring, multiple exposures, use of filters, etc. These operations on the image can be considered "analogue", even when done with digital tools.

What is amplified is in some way is the "scraps of the model" [12] (p. 139). In the "game of mirrors" between the referent and its representation, the distance between the two is often heightened. "The resemblance between the thing and its mirror image is only an exterior denomination that pertains to the thought. The ambiguous relationship of resemblance is, in things, a clear relationship of projection" [13] (p. 30).

What some photographs tend to create is essentially a new grammar of the image with which the edifice is shown through those manipulations that sublimate the raison d'être.

In one of his best-known series of photographs, Hiroshi Sugimoto [14] uses blurring to represent some iconic works of modern architecture (Figure 3a). He therefore creates a estrangement effect in which, however, the "familiarity" of the subject helps to reduce the distance. His diaphanous images seem to push the "vanishing point" away. They suggest that the image can thicken and become "clearer" but also propose the possibility that one is moving away from the subject.

Another theme that interests Sugimoto is the "representation" of time, the centre on which many of the Japanese artist's works are concentrated. Sugimoto particularly insists on this aspect, which sees particular development from time to time [15] (pp. 23-41). But it is in his project Theatres where "the images of the cinema... provide a condensed historical vision" [16] (p. 47). In Sugimoto's photographs, it is the time of the cinematographic projection that is condensed in the white image on the screen (Figure 3b).

Enclosing time in a single image is an aspect that Michael Wesely is also committed to. He depicts the transformation of the scene before the fixed eye of the camera. The result is a series of exposures-over the arc of three years-in which the results recall the signs that are condensed in Piranesi's prisons. The "what was" [9] (p. 86) is prolonged in time and is able to capture the modification of space through the deposition of "traces" that constitute a likewise impossible image (Figure 3d).

For his works characterized by an alteration of light, James Welling used two masterpieces of architecture as subjects. The Glass House by Philip Johnson is shown through coloured filters that give it an indirect, unexpected reading [17] (Figure 3e). Even more sophisticated are the digital manipulations made on Maison de Verre by Pierre Chareau, where the light defining the internal spaces is "rewritten" with reductions and amplifications (Figure 3c). 


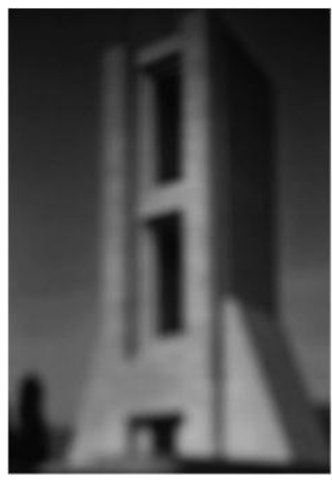

(a)

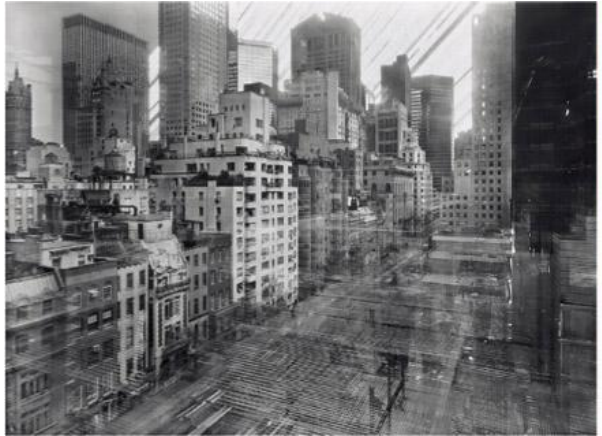

(d)

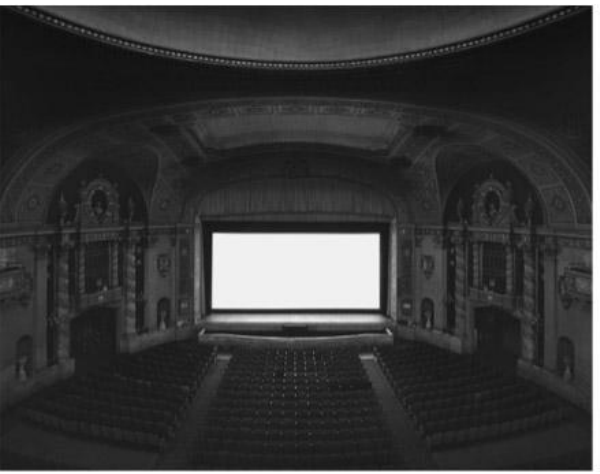

(b)

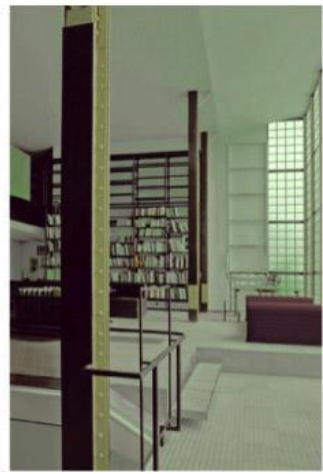

(c)

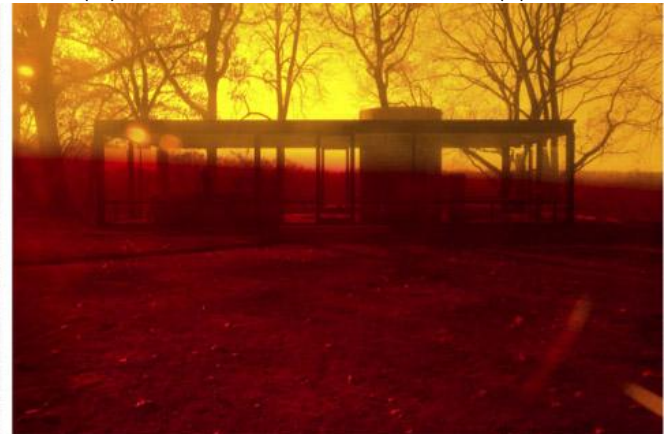

(e)

Figure 3. (a) Hiroshi Sugimoto, Architectures (Monumento Sant'Elia), 1998; (b) Hiroshi Sugimoto, Theatres (U.A. Walker), 2000; (c) James Welling, Maison de Verre, 2009; (d) Michael Wesely, Open Shutter (The Museum of Modern Art, New York), 9 August 2001-2 May 2003; (e) James Welling, Glass House, 2009.

Irene Kung also works with the manipulation of light to heighten the sense of isolation and abstraction in the buildings photographed [18]: "The beauty and mystery of Irene Kung's photos create a map of the city... the daily city transformed into the nocturnal city of dreams... The monuments preserve their identity and geographical location and, nevertheless, in abandoning the earth to rise towards the unconscious, are freed of their cultural and functional appearance to become admirable abstractions" [19] (p. 105) (Figure 4a).

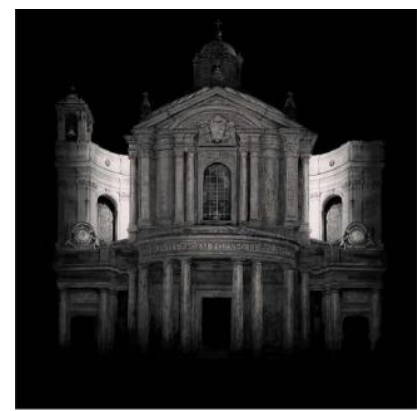

(a)

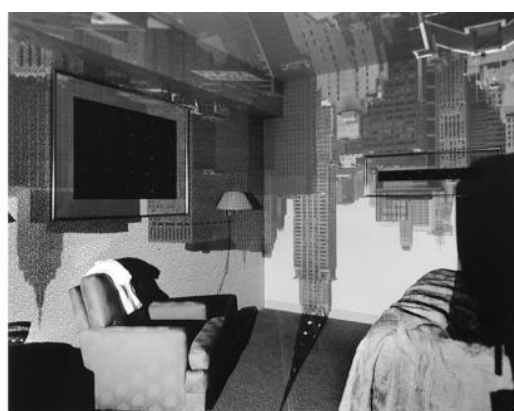

(b)

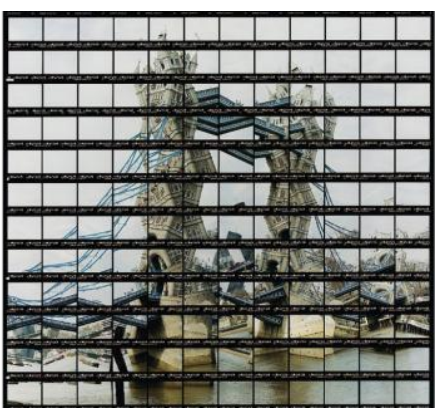

(c)

Figure 4. (a) Irene Kung, Santa Maria della Pace, Roma, 2007; (b) Abelardo Morell, Camera Obscura (New York), 1999; (c) Thomas Kellner, Tower Bridge, London, 2001.

The nucleus of the constitution of the image embodies the process implemented by Abelardo Morell in his project Camera Obscura [20]. The superposition of the external image-produced by the transformation of rooms into real camera obscuras - and the environments themselves produces a sort of photograph "squared": an indirect glance that builds a photograph of the "photograph" as the conclusion to a process that recalls what was begun by the main character in Italo Calvino's The Adventure of a Photographer (Figure $4 \mathrm{~b}$ ). 
Thomas Kellner also works on the theme of time. He represents architecture through successive snapshots that-making a deconstruction that also clearly references Cubism-frame partial sections of the buildings: the "fragments" are then reconstituted by laying printed strips of film side by side [21] (Figure 4c).

The figurations by Idris Khan - which only superficially appear close to Wesely's - originate in the superposition of multiple images but are applied through a complex process of stratification, thereby showing an "indefinite" reality composed of warp and weft. It is interesting to note how the images originate not only in original snapshots, but also in photographs by other artists; emblematic in this case is his work on some prints of the Becher couple [22] (Figure 5a).

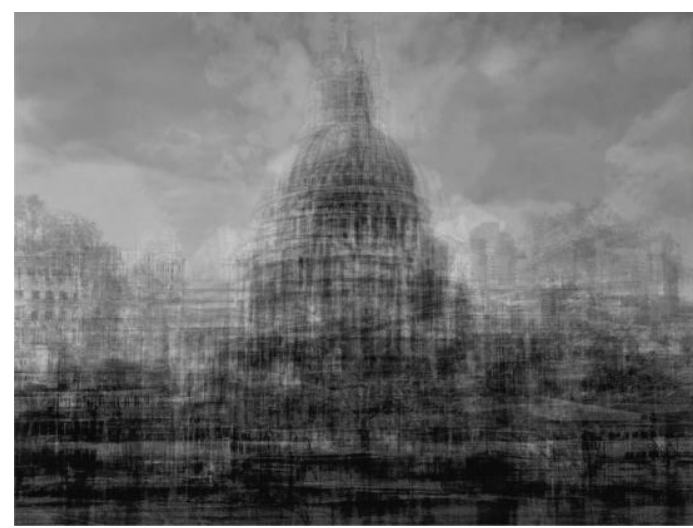

(a)

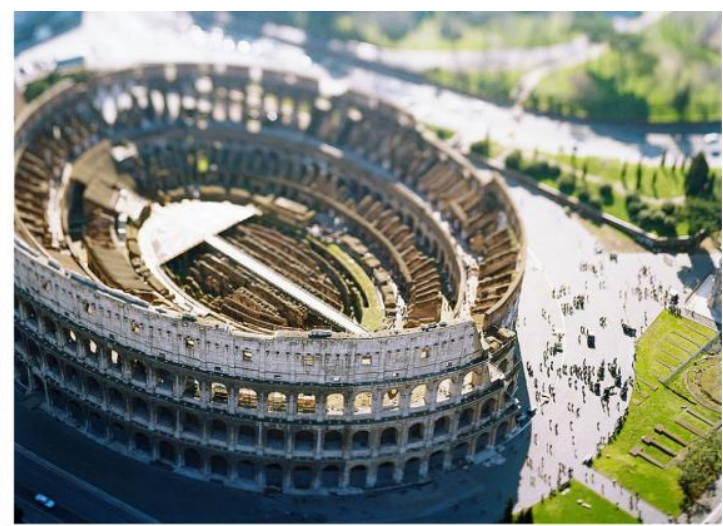

(b)

Figure 5. (a) Idris Khan, St. Paul's Cathedral, London, 2012; (b) Olivo Barbieri, Colosseo, Roma, 2004.

To close this section of the research, we cite the fascinating work of Olivo Barbieri, all of which is carried out within processes that use the constituent elements photography. Employing the tilt-shift method, Barbieri contracts the area of the shot in question. The process makes a selection and an invitation to the gaze. This, which is almost always from a high point of view, creates a distancing effect that transforms buildings and urban realities into a sort of scale model [23] (Figure 5b).

\section{2. "Artificial" Reality}

What is practiced is no longer an operation on reality. It is reconstructed through "simulacra", real scale models [24] that, with different degrees of abstraction or similarity, evoke and virtually reconstruct a possible reality.

In acting thus, the testimonial value of the image does not create problems (Barthes); it is the subject itself that causes problems for the conventions of what would normally be part of the photographic future. "The photograph abandons its traditional documentary worth, a tool capable of capturing the decisive moment, and introduces a doubt about what is seen and naively accepted as real" [25] (p. 35).

It is the "original" itself that is redefined. "The false truth of the copy gives body to a simulacrum that simulates the being itself to the point of substituting it (in the case of illusionism)" [12] (p. 139). The model, the replica, becomes the protagonist. "Today, abstraction is no longer of the paper, the double, the mirror, or the concept. Simulation is no longer of a territory, a referential being, a substance. It is the generation for models of a reality with no origin or reality: hyperreality" [26] (p. 10).

Thomas Demand uses paper to reconstruct real detail-rich "scenography" that is often inspired by real places and environments connected to particular social or political events. The almost obsessive reconstruction tends to simulate and to trick. Its images thus become a real criticism of the photographic representation of reality: what is depicted is only a simulacrum. The models, after being rigorously photographed, are destroyed [27] (Figure 6a).

The realism of James Casebere's models is different from that of other photographers analyzed here. He does not insist on the use of colour and the photographs seem to lack precise hints about the 
"scale". The use of water-as if the photographed spaces were flooded-also increases the sense of disorientation in his visions [28] (Figure 6b).

Emilio Pemjean instead selects spaces extracted from unrealized paintings and buildings. Through the neutrality of the surfaces, he reaches the heart of the character of the spaces represented. Light - the basic element of his constructions-becomes a tool for characterizing the environments depicted by his models. In addition to taking photographic snapshots, he also often makes videos that show a time series of how the spaces transform as the lighting is modified, thereby allowing for a real visual experience [25]. His project Palimpsesto - “...in a play of language transmutation that goes from architect to painting to sculpture and finally to the photo" [25] (p. 34) - "is a path through architectural works that now no longer exist-destroyed or radically transformed-but are still points of reference and collective myths that are perfectly identifiable thanks to some painted masterpieces". These works are reconstructed under the form of models, even "completing and reinterpreting the spaces in part blocked by objects that the painter used for the scenario" [25] (p. 34) (Figure 6d).

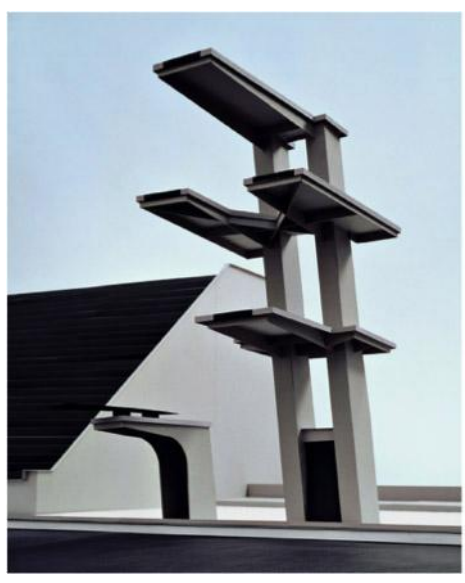

(a)

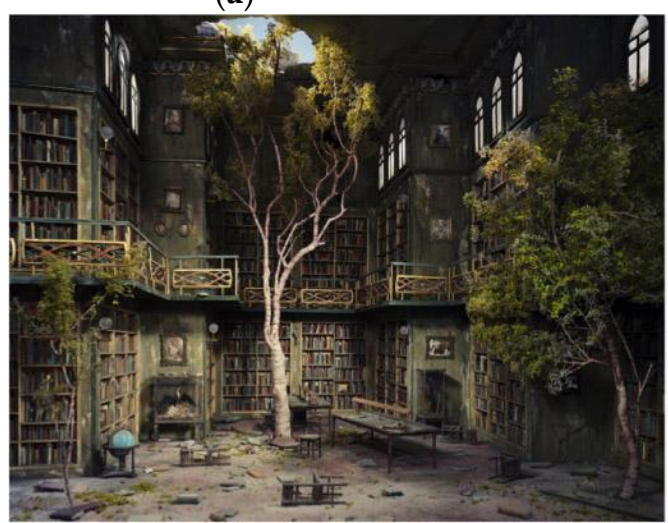

(c)

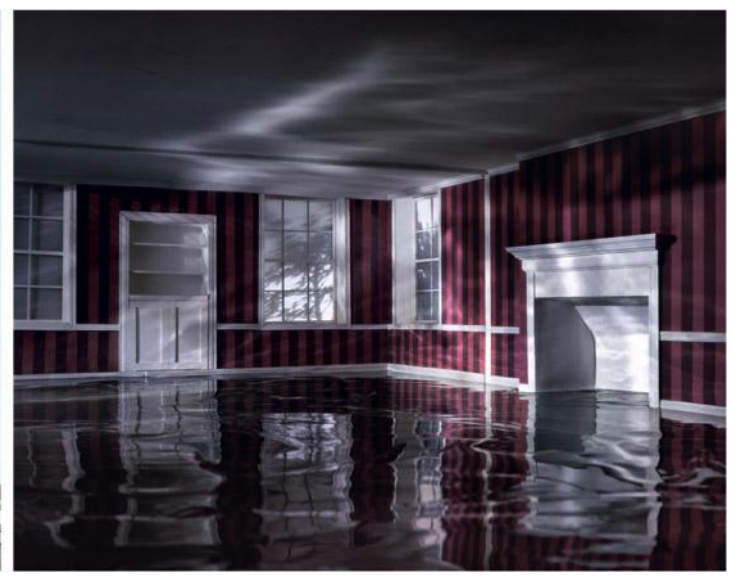

(b)

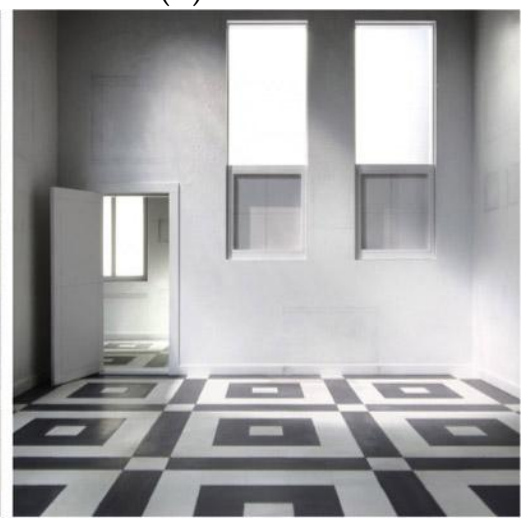

(d)

Figure 6. (a) Thomas Demand, Sprungturm, 1994; (b) James Casebere, Red Room, 2003; (c) Lori Nix, Library, 2007; (d) Emilio Pemjean, Oudezijds Voobugwal 320, Amsterdam, 2014.

Lori Nix's carefully created models insist on realism and the richness of detail, but they also represent particular conditions of the realized constructions. The American artist presents an apocalyptic vision where buildings are shown, after a hypothetical disaster, as ruins in a state of abandonment where nature seems to want to reappropriate the spaces [29] (Figure 6c).

\section{3. "Recreated" Reality}

In this last section, special elaborations are analyzed where architectural and photographic speculation is touched upon in a meaningful way that is entirely fascinating. An important group of artists start precisely from what exists, reinterpreting it and transforming it. In some cases, the 
"remounting" changes the forms and meaning to arrive at a new "construction" in which the relationship with the original becomes ambiguous and distant. In some cases a linguistic process begins that is constituted in a real formal sampling capable of evoking "other" realities.

Even just the removal of parts configures "another" reality. But the interventions on the parts of the image are often much more complex: duplication, alteration, deformation, editing, are the actions aimed at creating an image that-while maintaining a greater or lesser degree of similarity-largely reduces the relationship with a close referent.

The most important artist is certainly the German photographer Andreas Gursky. The image is disassembled and reassembled; the "correct" reality-through the removal of its components or their displacement-forms the figure of a condition that is not true but similar. Everything is presented in large-format prints that invite us to enter into these "new" realities [30] (Figure 7a).

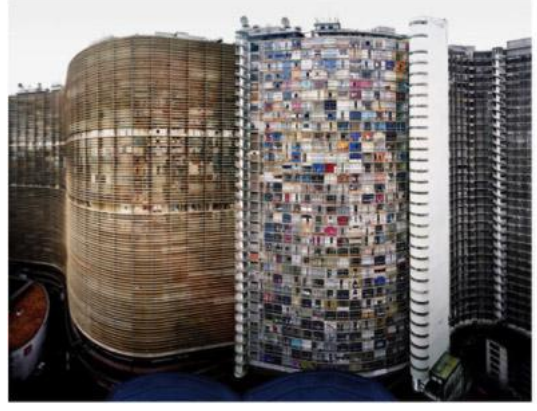

(a)

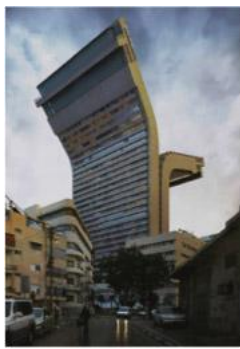

(d)

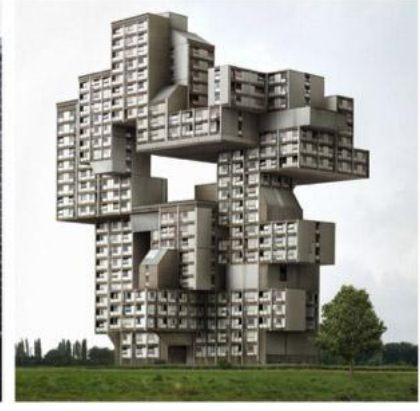

(b)

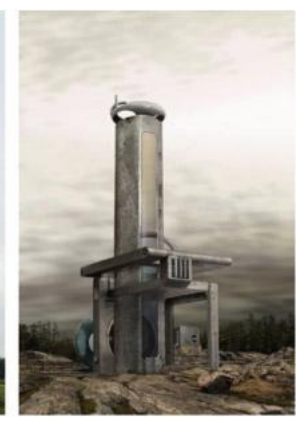

(c)

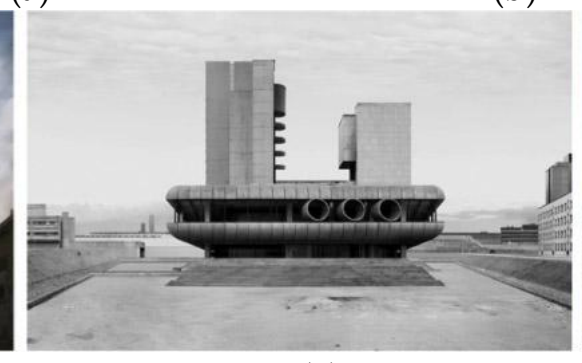

(e)

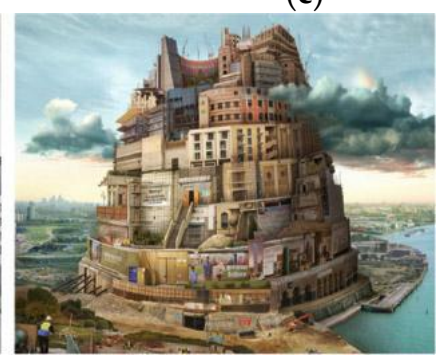

(f)

Figure 7. (a) Andreas Gursky, Copan, 2002; (b) Filip Dujardin, Untitled nr. 10, 2012; (c) David Trautrimas, The Fragment Accumulator, 2010; (d) Victor Enrich, Shalom nr. 1, 2009; (e) Beate Gütschow, S nr. 14, 2005; (f) Emily Allchurch, London Babel (after Bruegel), 2015.

The process proposed by Gursky is further developed in the work of other photographers that go further in their freedom to use parts that are assembled in the search for original forms.

Beate Gütschow, in her "S" [Stadt] series of images combines numerous fragments of urban construction-photographed in some of the most important cities in the world-creating images that evoke, despite the evident fiction, post-apocalyptic city spaces with great realism. The use of black and white also participates in creating an atmosphere capable of fascinating suggestions. Gütschow's desire is to establish a story. If reality is not shown to be capable of providing the "right" elements for this, then it is constructed specifically for it. It is worth noting the presence of the human figure, or in its absence, of elements that in some way mark the presence of humans, who continue to inhabit the scenes represented [31] (Figure 7e).

Filip Dujardin, while proposing a repertoire of more "extreme" forms, composes his architectures in a manner not unlike the one used by Gütschow. In this case editing also starts by capturing parts of real constructions that are "reused" to build new realities, which are often inserted in a natural context where human presence is not excluded [32] (Figure 7b).

The work of David Trautrimas can be compared to the work of artists mentioned above, but only from the point of view of constructing the image. Because if the mechanism is certainly shared, the elements are decidedly different. Trautrimas uses objects taken from reality, but used in building architectural structures creates a estrangement effect given by the transformation of the original 
function and the modification of scale. With a mechanism that is ready-made and not without an undoubted element of fun, the objects loan themselves to building imaginary buildings. The images that constitute his Spyfrost Project series evoke individual building-machines such as military structures used for a hypothetical "cold war" [33] (Figure 7c).

The compositional procedures implemented by Victor Enrich are not unlike those described up to now. The particularity of the Catalan photographer is his composition of extreme structures that call into question any static convention. In addition, when he imagines buildings as capable of having different structures, transformation and movement is not unusual, and everything is underlined by the construction of sequential images (Figure 7d).

Beyond the established processes-similar to those of other artists discussed here-the characteristics of Emily Allchurch are the use of famous paintings as an iconographic reference for her images. Her depictions therefore become real rewritings of works such as The Tower of Babel by Pieter Bruegel the Elder or Giovanni Battista Piranesi's Prisons, but they also use fragments of contemporary buildings. The fascination of her work grows out of the clear recognizability of the "original" work and the subsequent discovery of the particularities of the elements that compose the elaborations (Figure 7f).

In the work of the Finnish artist Ilkka Halso, the protagonist of the snapshot is no longer the architecture. Combining natural scenarios with architectural structures in the series Museum of Nature, "he shows an image that is anything but pure and uncontaminated-but so often appreciated - of nature. Rather, his works present nature torn from its environment... the images place before the observer's view a completely unnatural reality, new and never seen before: a digitally developed reality that Halso obtains by assembling photographs of landscapes and 3D computer-generated models" [34] (p. 109) (Figure 8a).

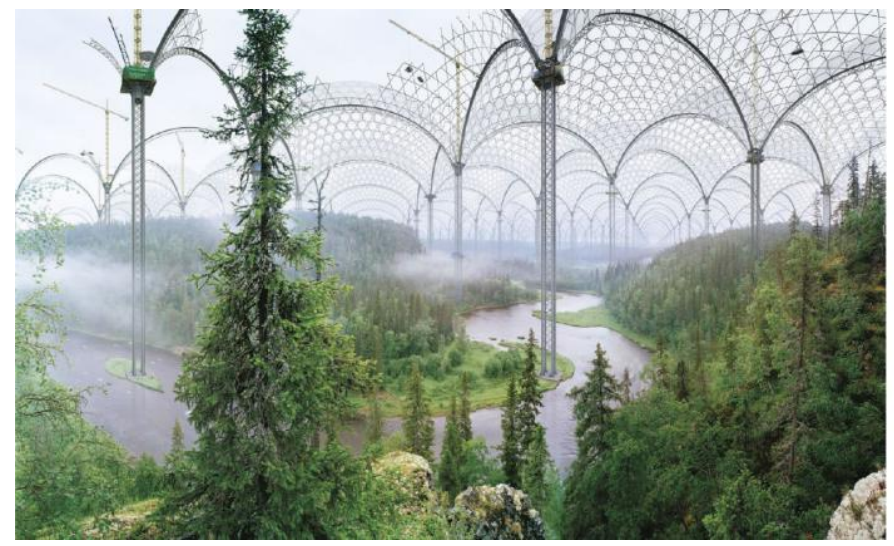

(a)

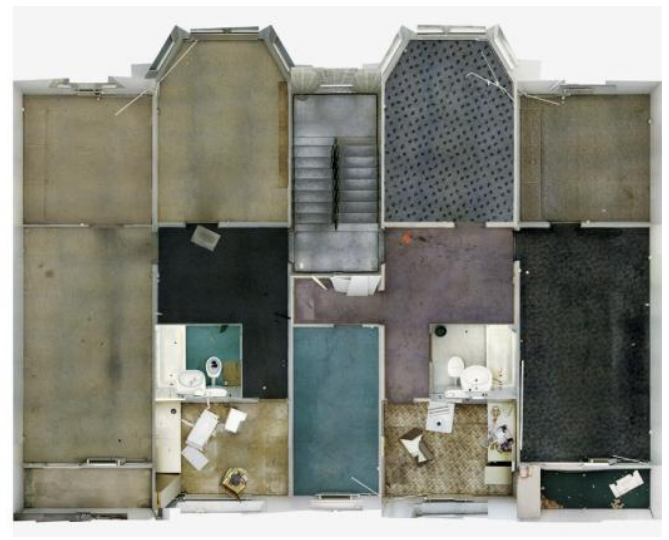

(b)

Figure 8. (a) Ilkka Halso, Museum of Nature, Kitka-river, 2004; (b) Andreas Gefeller, Plattenbau 4, 2004.

The images by Andrea Gefeller [35] go well beyond a desire to realistically simulate real points of view. Reality is reconstructed through complex photography operations in order to simulate an infinite point of view: "The title of the series Supervision already contains a reference to the chosen perspective... The characteristic of these images is in the perspective from above that shows us the rooms as if they lacked ceilings. An unrealistic and almost distancing vision is therefore created, in conflict with the common way of seeing a place" [34] (p. 88) (Figure 8b).

It seems obvious how photography and some of its developments have caused a crisis in recent years in its relationship with reality, which seems to be dissolving more and more [36]. Even if the relationship with reality is anyway maintained in the examples that have been considered, one sees the complete release from it increasingly often in some artists' work, along with the creation of completely synthetic images.

The next level coincides with the total disappearance of a real referent, instead being projected in a completely reconstructed virtual digital scene. Works by Giacomo Costa [6] (pp. 119-143) and 
Alex Roman can be mentioned among the most important examples, while considering an important difference in the approach and results.

\section{Conclusions}

In this investigation on the manipulation of the image in photography and architecture, what is evidenced is a certain complementarity of the two worlds, which go beyond their original disciplinary confines to fill in voids and cracks in the other discipline. On the one hand, the contemporary architecture of real estate announcements seems increasingly like a projection of the image (selling then building), as in photography, which looks for "genuine" three-dimensional models for two-dimensional representation. Where those values of which architecture would have had to be a protective deity are no longer recognized in reality, its subjects are created ex novo. On the other hand, the work of architect-collage artists makes precisely the aura that the photograph confers on reality return to architecture that depth of which the consumption society has ruinously removed.

A search for the key word evinced by these reflections on architecture and photography could therefore result in "model". Architecture and photography historically need formal models and tools for abstraction to be able to speculate in an orderly way (the role of descriptive geometry in the theory of both disciplines comes to mind), but the standardization and commercialization of the contemporary age have dominated the models of the past with signs, concealing them or emptying them of their original meaning.

The multi-sensory chaos in which we are immersed makes reality in itself unmanageable for effective artistic investigation. To be able to produce meaning, it is necessary to isolate fragments or autonomously generate spaces that are quieter and less saturated with information. And precisely the search for signs, therefore, could be the common meaning behind the various modulations of photographic manipulation, surprisingly the opposite of falsification and counterfeiting. The search for the project recognizes in the photographic image an ordering tool because it selects memories of spaces and times, while photographic experimentation proposes new geometries and paradigms to be able to silence, at least in the time of a click, the perceptual conflict of an overcrowded reality that masks its bearings.

Acknowledgments: N.B. All direct quotations were translated by the author from the bibliographic sources.

Author Contributions: This work was conceived and designed by Marta Magagnini e Nicolò Sardo. Marta Magagnini has developed and edited the Section 2, Nicolò Sardo the Section 3.

Conflicts of Interest: The authors declare no conflict of interest.

\section{References}

1. Ceserati, R. L'occhio della Medusa. Fotografia e Letteratura; Bollati Boringhieri: Turin, Italy, 2011.

2. Siegel, E. Playing with Pictures: The Art of Victorian Photocollage; Art Institute of Chicago: Chicago, MI, USA, 2009.

3. Berger, J. Sul Guardare; Bruno Mondadori: Milan, Italy, 2003.

4. Fanelli, G. Storia della Fotografia D'architettura; Laterza: Rome, Italy, 2009.

5. Stockel, G. Fotografia Come Fatto Mentale. Guardare Vedere Fotografare; Edizioni Kappa: Rome, Italy, 2007.

6. Magagnini, M. PICarchitecTURE. Il Medium è il Montaggio; Letteraventidue: Siracusa, Italy, 2013.

7. Rowe, C.; Koetter, F. Collage City; MIT Press: Cambridge, MA, USA; London, UK, 1983.

8. Galofaro, L. An Atlas of Imagination; DAMDI: Seoul, Korea, 2015.

9. Barthes, R. La Camera Chiara. Nota Sulla Fotografia; Einaudi: Turin, Italy, 2003.

10. Wunenburger, J.-J. L'immaginario; Il Melangolo: Genoa, Italy, 2008.

11. Black, M. Come rappresentano le immagini. In Arte Percezione Realtà. Come Pensiamo le Immagini; Gombrich, E.H., Hochberg, J., Black, M., Eds.; Einaudi: Turin, Italy, 1978; pp. 115-157.

12. Wunenburger, J.-J. Filosofia delle Immagini; Einaudi: Turin, Italy, 1999.

13. Merleau-Ponty, M. L'occhio e lo Spirito; SE: Milan, Italy, 1989.

14. Sugimoto, H. Sugimoto: Architecture; Hatje Cantz: Ostfildern, Germany, 2007. 
15. Sugimoto, H. Fermati tempo. In Hiroshi Sugimoto. Stop Time; Maggia, F., Dall'Olio, C., Eds.; Skira: Milan, Italy, 2015.

16. Bruno, G. Atlante delle Emozioni; Bruno Mondadori: Milan, Italy, 2006.

17. Elcott, N.; Lavin, S. James Welling. Glass House; Damiani: Bologna, Italy, 2010.

18. Kung, I. La Città Invisibile; Contrasto: Rome, Italy, 2012.

19. Prose, F. La città del sogno. In La Città Invisibile; Kung, I., Ed.; Contrasto: Rome, Italy, 2012; pp. $103-106$.

20. Morell, A. Camera Obscura; Bulfinch Press: New York, NY, USA, 2004.

21. Kellner, T. Ozymandias; Ffotogallery: Canton, Cardiff, 2003.

22. Kahn, I. A World Within; Hatje Cantz: Ostfildern, Germany, 2017.

23. Tognon, P. Olivo Barbieri. Virtual Truths; Silvana Editoriale: Cinisello Balsamo, Italy, 2001.

24. Sardo, N. La Figurazione Plastica dell'Architettura. Modelli e Rappresentazione; Edizioni Kappa: Rome, Italy, 2004.

25. Pemjean, E. Palimpsesto. Domus 2014, 986, 34-37.

26. Baudrillard, J. Simulacres et Simulation; Galilée: Paris, France, 1981.

27. Bonami, F.; Durand, R.; Quintin, F. Thomas Demand; Thames \& Hudson: London, UK, 2000.

28. Casebere, J. The Spatial Uncanny; Charta: Milan, Italy, 2001.

29. Nix, L. The City; Decode: Seattle, WA, USA, 2013.

30. Beil, R.; Feßel, S. (Eds.) Andreas Gursky: Architecture; Hatje Cantz: Ostfildern, Germany, 2008.

31. Bischoff, U.; Gebbers, A.-C. Beate Gütschow: S; Hatje Cantz: Ostfildern, Germany, 2009.

32. Leão Neto, P. Reading Fictional Structures through Digital Photography. Scopio 2010, 11/3, $18-37$.

33. Namias, S. David Trautrimas: Habitat Machines. Zoom 2011, 96-99.

34. Marangoni, M.; Nori, F.; Rogers, B.; Sabau, L. (Eds.) Realtà Manipolata. Come le Immagini Ridefiniscono il Mondo; Alias: Firenze, Italy, 2009.

35. Uthemann, E.W. Andreas Gefeller. Photographs; Hatje Cantz: Ostfildern, Italy, 2009.

36. Higgott A., Wrany T., Eds. (2012), Camera construct. Photography, Architecture and Modern City. London: Routledge. 